\title{
Secular deformations of the sand ground of Golgotha Mount on the Anzer Island of the Solovetsky Islands in the White Sea
}

\author{
Sergei Chernyshev ${ }^{1}$, Andrew Lavrusevich ${ }^{1 *}$, Irina Evgrafova $^{1}$, and Nikolay Chernyshev ${ }^{2}$ \\ ${ }^{1}$ Moscow State University of Civil Engineering, 129337, 26, Yaroslavskoye Shosse, Moscow, Russia \\ ${ }^{2}$ Ministry of Culture, Moscow, Russia
}

\begin{abstract}
Very slow secular horizontal movement of ground is commonly not taken into consideration during construction of buildings near slopes and bents with no risks of landslide. However, our observations indicate that a range of objects is marked with such movement. Current study is aimed at determining the rate of the sand ground dislocations near the ultimately steep slope. In order to determine the rate, we conducted periodical measurements of the width of the tensile fractures in the loadbearing walls of the building constructed in 1830. Building of the object and its restoration in the current century have led to the imperfect structure of the building, lacking steel ties in the brick walls, which should have been installed at different levels, specifically under the floor and at the level of the vault abutment. The absence of ties has resulted in rupturing of the examined building due to tensioning of the moving foundation. The errors of the constructors have transformed this building into an object that can be used to determine the rate of ground movement.It is not a unique case, as this small velocity is often neglected, which, however, results into the wall fracturing in the course of long-term use.
\end{abstract}

\section{Introduction}

It is generally accepted in engineering geology and geotechnics that sand ground does not undergo plastic deformation at the slopes, however, long-term observations allow the researchers to detect steady horizontal movement under load. Our studies on deformation of the natural sand soil massif were conducted at Golgotha Mount, located on one of the islands in the White Sea and called after the famous mount in Jerusalem [1]. Deformation of the foundation leads to fracturing of buildings and other structures, making the studies on the deformation rates an issue of vital importance.

* Corresponding author: lavrusevich@yandex.ru 


\section{Methods, engineering and geological conditions of the study}

Periodical measurements of the width of fractures, assessment of their expansion is the approach to determining the rate of secular deformation of the sand ground under the building. The width of fractures was measured with a beam compass within the accuracy of $0.1 \mathrm{~mm}$ at the specific location, determined within the accuracy of $0.25 \mathrm{~mm}$. The temperature of the environment was also tracked, as the width of fractures depends on the temperature. All the measurements were conducted in June, when the temperature is quite stable due to the impact of the surrounding sea, as the island is just $4.5 \mathrm{~km}$ wide.

The Church of the Crucifixion, located on Golgotha Mount, has been being renovated in consultation with the author since the beginning of current century. The church was built of red brick in 1828-1830. The author performed examination and visual assessment of the restored constructions and measured the fractures in 2000, 2002, 2008 and 2015.

The mount is a large hill. Its absolute height is 63.8 meters. The contour lines of the mount are elliptical, with the major axes going from west to east. These features provided an opportunity to build a ship-like church (figure 1) with a chancel apse, a quadrangular frame, a bell tower, and the auxiliary buildings with the cells.

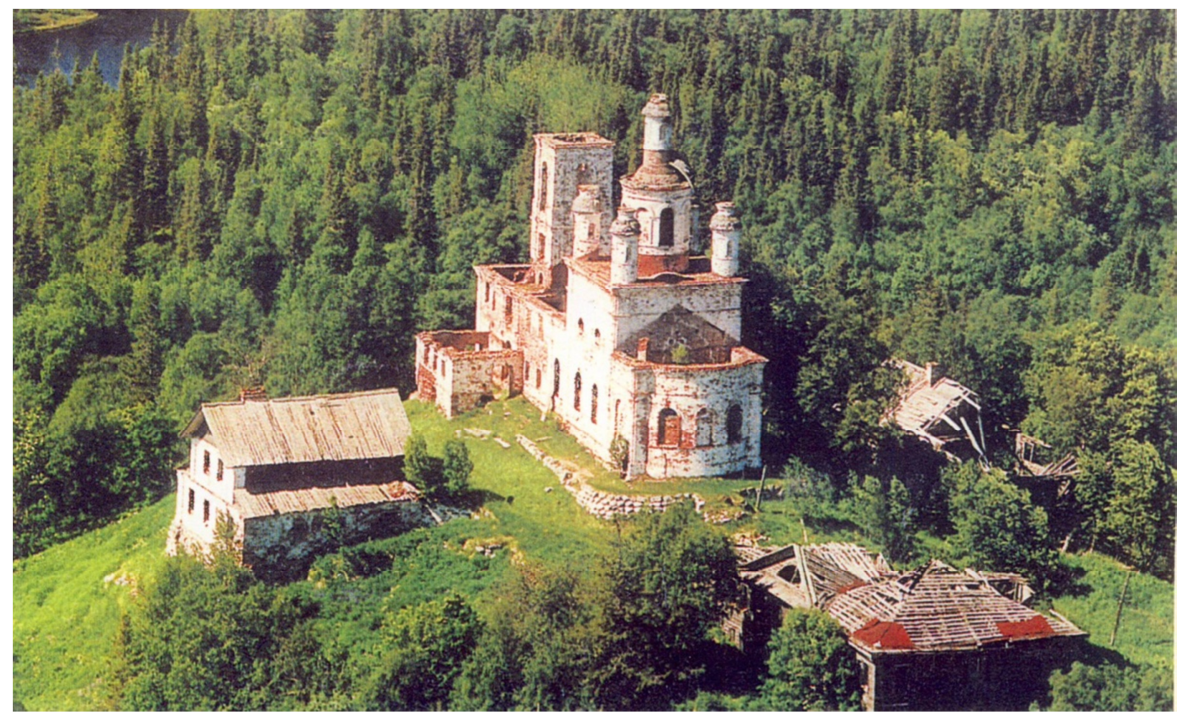

Fig. 1. General view of Golgotha Mount with the church on the top, 2000.

All the elements of the building are oriented along the east-to-west longitudinal axis (figure 2). The western part of the construction consists of small chambers. It includes longitudinal and transverse bearing walls, providing higher rigidity, solidity of the whole structure. The eastern part of the building -the refectory and the chancel, are, on the contrary, relatively large, thus being less rigid. The quadrangular frame and the chancel lack the necessary steel tie-beams, that are usually implemented in such structures. Therefore, the church undergoes thrust deformation under the weight of the vaults and the movement of the soil. We analyzed the patterns of the fractures in the bearing walls and proved that they are not caused by thrust exclusively. 


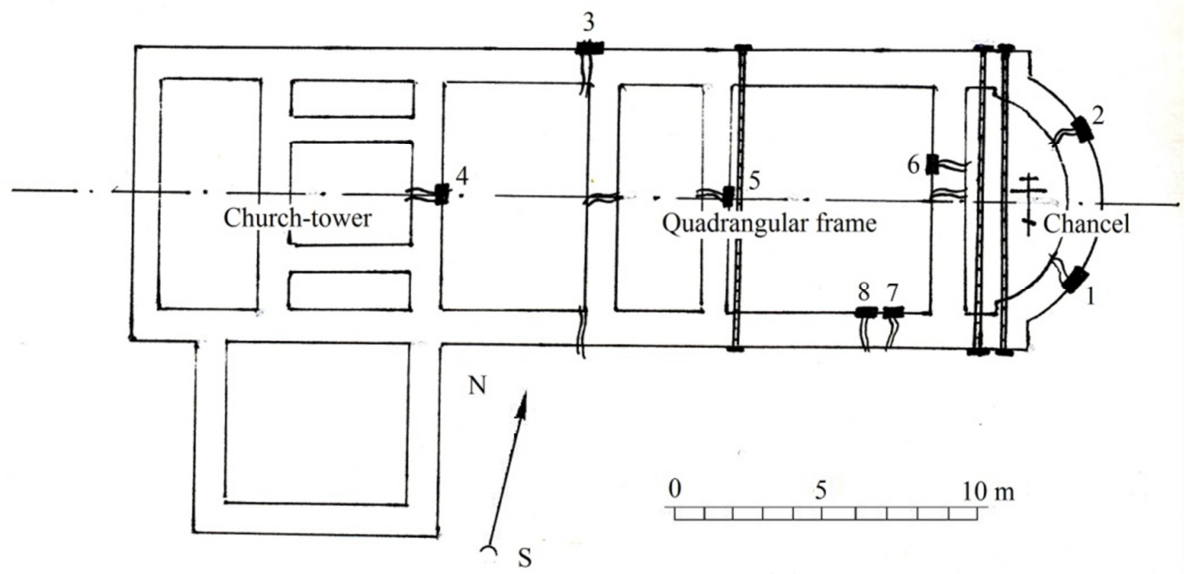

Fig. 2. Structure plan specifying the location of the telltales on the fractures 2000.

The church is surrounded with the 2 to 3.5 meters-wide earth-filled terrace with a dryboulder revetment. The church stands on the fluvioglacial sands of the mechanical composition varying from sandy silt to gravelly, with coarse inclusions, up to the size of boulders, with sandy loam and loam alternations, constituting a small fraction of the profile. At the depth of 2.2-3.0 meters, the air void ratio of the sands varies from 0.46 to 0.72 , with an average of 0.6 , therefore, the sands can be considered to have high and middle density, and the values of the modulus of deformation, E, MPa, varying, based on the size of the particles, from 25 for fine sands to 50 for coarse sands. The 0.5-0.7-meter thick layer of loam strip directly underlies the rubble stone footing of the church. It is the base layer of the foundation, heavily packed under the church footing. Its air void ratio is equal to 0.5 , the modulus of deformation $E=33 \mathrm{MPa}$, the angle of internal friction $\varphi=25^{\circ}$, cohesionC $=37 \mathrm{KPa}$. The slopes of the mount descend from the leveled site at an angle of $31-33^{\circ}$, which is very close to the natural slope of the sands of the mount.Apparently, in the course of the levelling performed at the beginning of the $18^{\text {th }}$ century and predominantly at the beginning of the $19^{\mathrm{th}}$ century, when the top of the hill was cut to create the building site, the sand soil was dumped on the slopes, fastened with the revetment, and partially covered the bents at an angle of the natural slope.

The layers of argillaceous material withhold thin lenses of subsurface water. In the $18^{\text {th }}$ century, a well, containing water at a small depth, was located near the wooden church that used to be here. According to the Life of Saint Job, the well was dug in a single day. The water was found soon after the beginning of trenching, suggesting that the level of perched groundwater was no deeper than 2 meters. The site for the wooden church was markedly smaller than the modern one. Its absolute level was higher than that of the modern site. The loamy layer, currently underlying the strip foundation of the church, was buried with sands. The groundwater lens, located in the sands, was nourished with the water all over the surface of the top of Golgotha Mount and the roof drainage of the wooden church. During grading and levelling for the stone church, the water-carrying pocket was dismantled. The church overlapped the whole surface of the loamy layer, thus preventing the water inflow, which led to depletion of the aquifer stratum. In 2000, before the beginning of restoration, we did not observe any signs of perched groundwater under the church foundation, although the client had set a task of finding subsurface water on the top of the mount. 


\section{The results of observations on the expansion of the fractures in the building}

The church building was architecturally restored in July to August 2007, when the faces and the interior were plastered (figure 3). Through cracks emerged in these structures. Prior to restoration, the bearing walls of the eastern part of the church had major fractures (figure 2).

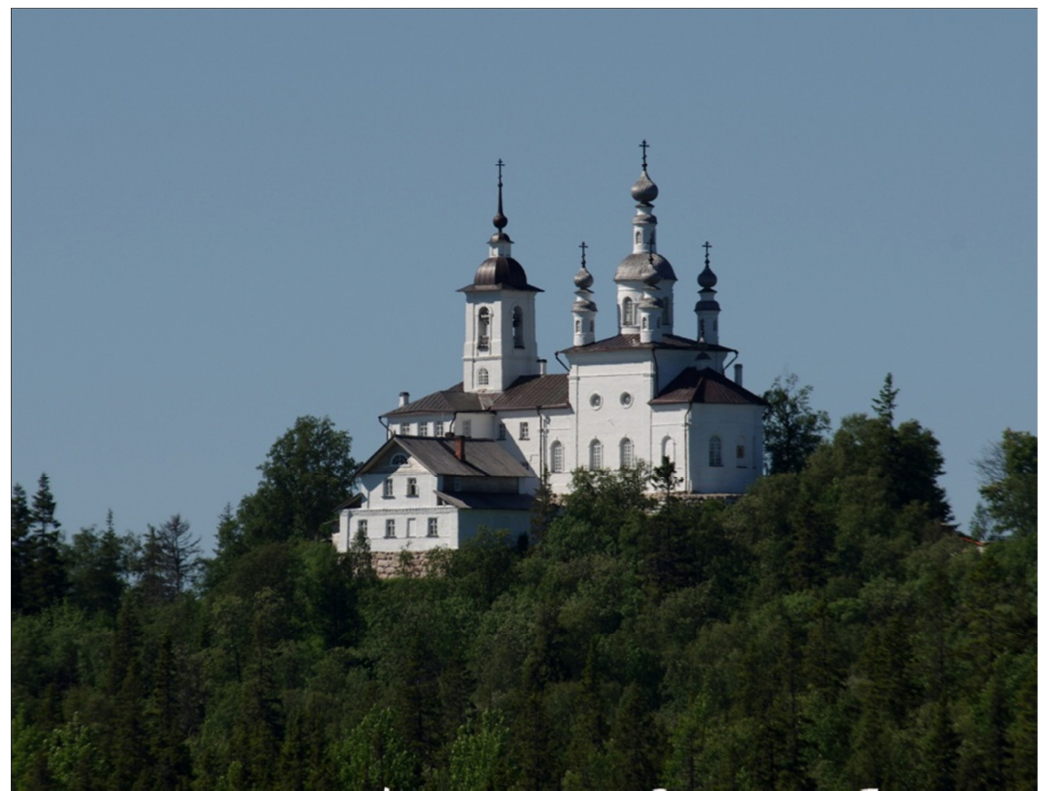

Fig. 3. The church on Golgotha Mount after the restoration, 2008

The largest fracture went along the church axis from the chancel apse through the eastern and the western walls of the quadrangular frame (figure 4). Four reasons for the formation of through cracks in the walls of the building can be listed: 1) thrust of the five-headed dome of the quadrangular frame and the apse dome, 2) presumed plastic flow of the hill soil under load of own weight and the building on the top of the hill, 3) temperature deformation, 4) local suffusion decompaction of the footing [2,3].Seasonal variations of temperature with the amplitude of approximately $60^{\circ}$ allows one to assume recurrently emerging temperature stress within the church brickwork, adding to the stress caused by the weight of the building and the geological processes in its footing. The fracturing pattern indicates the influence of the four listed factors and some other ones. The short horizontal fracture of the wall brickwork uplifting from the boulder foundation with an opening of approximately $10 \mathrm{~cm}$ (figure 5) was, undoubtedly, caused by suffosion due to runoff water, flowing from the roof during the period of abandonment, lasting from 1940 (liquidation of the Solovki prison camp) to 2000 (arrival of the monks to the island, reestablishment of the monastery). The fracture along the church axis in its eastern, structurally weaker part, indicates both thrust and dislocation of the walls. These factors are superimposed. However, the maximal opening of the fractures is observed at the eastern wall, predominantly at the wall base. Low apses cannot cause the maximal thrust stress here. Therefore, the apse is tensioned in the northern and the southern directions due to the stress originating in the footing, as the fractures are wider at the base of the wall. Thrust fractures would have a different pattern, on the contrary, opening from the top and narrowing to the bottom. 


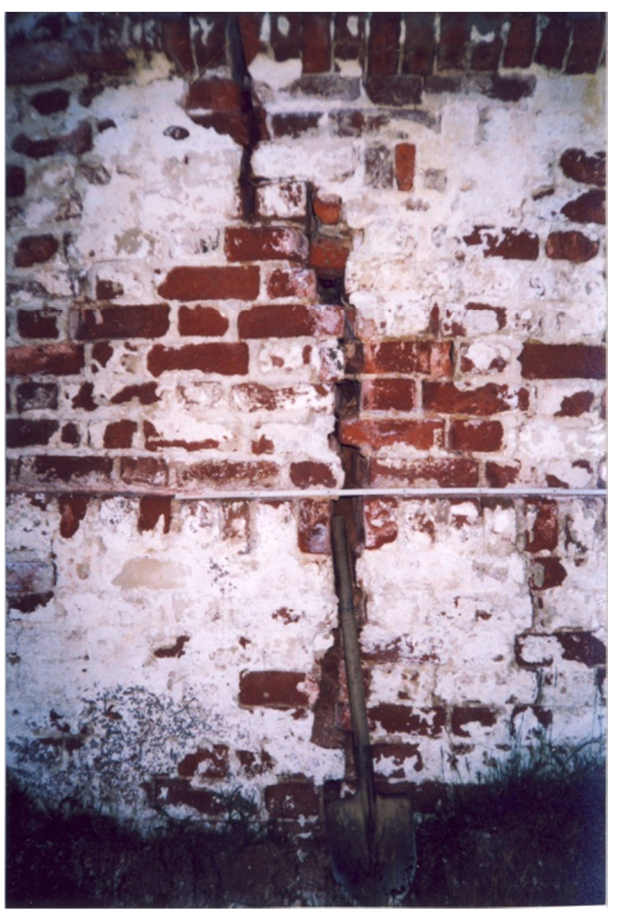

Fig. 4. Vertical fracture in the chancel wall, 2000

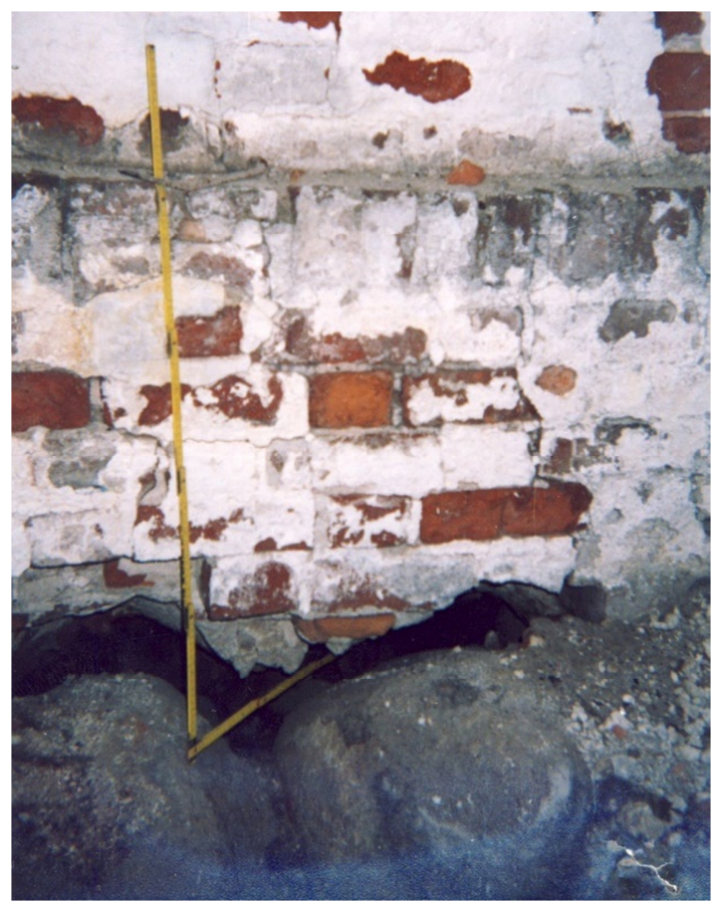

Fig. 5. Horizontal fracture of the wall brickwork uplifting from the rubble boulder foundation, 2002. 
In 2000 and 2002, the northern and the southern bearing walls, precisely in the middle part of the building, had fractures, caused by the movement of the western solid and heavy part of the church in the western direction, toward the steepest slope of Golgotha Mount. One could assume similar movement of the eastern part to the east, but this slope is gradual, approximately $15^{\circ}$, whereas the upper part of the western slope has an angle of $35^{\circ}$, the middle part is more gradual, with an angle of $25^{\circ}$, reaching $20^{\circ}$ in the lower part (figure 6).
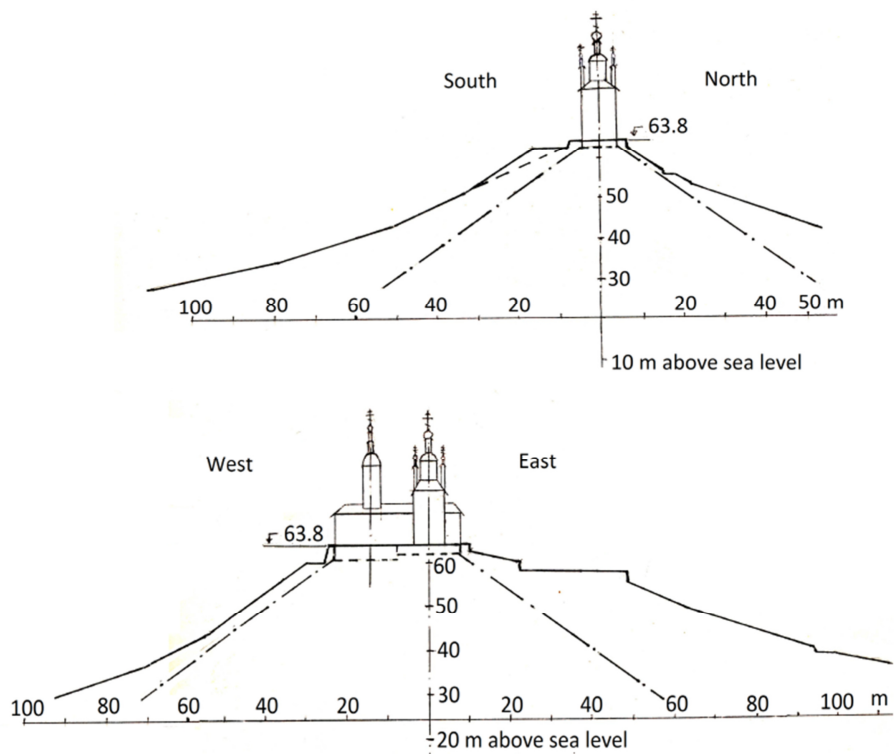

Fig.6. Profiles of Golgotha Mount: top - along the south-to-north direction, bottom - along the west-toeast direction. Dotted line indicates the natural slope angle.

In June 2000, the fractures on the external side of the apse, in the window openings, were up to $50 \mathrm{~mm}$ wide (figure 4). Total width of the fractures in the eastern wall of the church was $90 \mathrm{~mm}$. The plaster telltales, installed in 2000, had not been broken by June 2002. The telltales were destroyed during the restoration. After the restoration, by June 2008, fracturing of the carrying structures had resurged. The tasks of improvement of the building structure, including construction of tie beams that are installed in order to resist thrust caused by the vaults of the quadrangular frame and other arcs, anchorage of the walls at the fracturing sites, have not been solved during the renovation. Binding of the northern and the southern walls under the church floor, recommended by the exploration engineers, has not been performed. Due to these reasons, thin fractures have re-emerged as soon as by 2008, subsequently opening and lengthening. On June $10^{\text {th }}, 2015,5$ fractures with the measured opening of $0.1 \mathrm{~mm}$ and less were observed in the northern window of the chancel on the external side of the apse at the temperature of $12^{\circ} \mathrm{C}$. Total opening of the fractures under the northern window was $0.3 \mathrm{~mm}$. Under the southern window, 4 fractures were observed, with the openings varying from 0.05 to $0.5 \mathrm{~mm}, 0.9 \mathrm{~mm}$ in total. In 2015, total width of the fractures in the eastern wall of the church at the level beneath the window openings was $1.2 \mathrm{~mm}$. The fractures continue above the window openings. In the chancel, the same fractures can be observed above the window openings on the internal wall of the apse; some of them reach the width of $0.5 \mathrm{~mm}$, according to visual assessment.A group of thin fractures can be seen in the vault above the chancel, near the junction of the vault and the eastern wall of the quadrangular frame. No fractures have been observed in the wall of the quadrangular frame from the chancel side since 2015 . The fractures 
occur in the northern and the southern walls of the quadrangular frame, for instance, a $0.1 \mathrm{~mm}$ wide fracture can be seen under the eastern window of the southern wall, going from the base of the wall to the window. It continues up to 1.2 meters above the window. All the observed fractures are vertical and through. The largest interior fracture can be seen in the northern wall, to the west from the quadrangular frame, above the third window from the chancel. Its opening is approximately $0.5 \mathrm{~mm}$. The fracture goes from the wall to the vault, continuing up to $1.7 \mathrm{~m}$ across the vault, perpendicularly to the major axis of the church.

\section{Discussion of the results of the observations on the expansion of the fractures in the walls of the church}

According to the total opening of the fractures in the eastern wall of the church, the rate of separation of the northern and the southern bearing walls after the restoration was approximately $0.16 \mathrm{~mm} /$ year. Over the period from 1830 to 2000 , the velocity of separation of the church walls was about $0.5 \mathrm{~mm} /$ year, as calculated on the basis of the opening of the fractures, shown in figure 2 and figure 4 . The values of the velocity are of the same magnitude, but three-fold different. The direction of the velocity vector, according to the pattern of the tensile fractures, has not been changed over the whole history of the church since 1830 . It is possible that the differences in the values were caused by temporal inconsistency of the fracture expansion. Nonuniform rates of the fracture expansion are confirmed by the fact that the telltales on the fractures were not broken over two years, from 2000 to 2002, but the expansion resumed in less than a year after the end of restoration in 2007, by the beginning of the summer 2008. Probably, the rapid escalation of the fracture expansion coincides with the coldest years, when the tensile stress, caused by thrust and separation of the hill, is accompanied with major temperature stress. It is possible that significant expansion of fractions occurred during the period from 1940 to 2000, when the church was not heated, and the temperature stress in the brickwork reached maximal values during the extremely cold winters in the early 1940s. It would lead to higher values of the average secular velocity over the period before 2000. At the same time, suffosion in the outer surface of the footing promoted separation of the church walls. This is when the footing was torn from the wall at the site of decompaction of the foundation, caused by suffosion and marked by the suffosion sinkhole observed in 2000 near the church wall.

Future projected expansion of the fractures in the chancel apses can lead to the total opening of approximately $3 \mathrm{~mm}$ by 2025 .

\section{Conclusion}

To sum up, according to the fractures, Golgotha Mount undergoes slow plastic deformation under its own weight and the load of the building. Due to this process, before the restoration, according to our observations in 2000 , the church walls had through fractures, up to several centimeters wide, indicate the movement of the northern bearing wall to the north and the southern bearing wall - to the south. The western part of the church, built as a solid construction, was moving to the west, as the western slope of the mount is the steepest one. During the restoration of the church, the ties were not made. According to our observations in the summer 2015, fracturing of the church has resumed. Currently, the fractures are not dangerous and do not affect the interior; however, if our hypothesis on plastic deformation of the sand mount is correct, they will undergo continuous, although not quite steady, expansion.

The presence of the fractures in the bearing walls of the building, given small opening, could raise no fears, but the situation is exacerbated by the fact that, after the adoption of the 
new edition of Russian construction standards and regulations [4] for earthquake-resistant construction in 1997, according to the map of general seismic classification OSR-97-V, the Anzer Island is located in the seismic region with the score of 7 and a 5\%-probability of higher scores. According to the conditions of seismic microclassification, the building on the top of the hill, standing on the sandy soil, is in an adverse environment. Therefore, preparations for a possible earthquake in line with modern regulations require seismic microclassification of Golgotha Mount and assessment of the soil stability under the conditions of the projected earthquake action. This issue is particularly important due to the latest trend of increasing earthquake intensity within the earthquake zones [5].

Revealed secular plastic deformation of the sandy soil require improvement of the building structure, considering the tensile stress, perpendicular to the west-to-east axis of the church, creation of a concrete belt at the level of the footing and of the ties for this belt in the number of planes along the velocity vector of the tension of the bearing walls of the church, determined from the fractures.

Our observations on the secular deformation can be useful all over the world for the purposes of construction of new buildings on the sandy soil near bents and slopes, as well as for renovation of the existing structures in the constrained urban environment during the roadway excavation.

\section{References}

1. S.N. Chernyshev, I.M. Evgrafova, M.A. Neklyudov, News of universities.Building. № 8, 107-114 (2014)

2. Lu. Shenpin, A.M. Martynov, A.M. Kabirov, S.N. Chernyshev, A.A.Lavrusevich, Industrial and civil construction, №. 12, 85-91 (2017)

3. I.A. Lavrusevich, A.I. Podlesnykh, A.A. Lavrusevich, Eng. Geo., №. 3, pp. 44-51 (2017)

4. Construction in the earthquake areas. SNiP II-7-81*. Official edition.FGUP TsPP. M., (2004)

5. A.D. Potapov, I.L. Revelis, S.N. Chernyshev, Earthquakes. Origin, consequences, safety precautions (2017) 